\title{
Frontline yet at the back of the queue - improving access and adaptations to CBT for Black African and Caribbean communities
}

\author{
Leila Lawton ${ }^{1 \star(1)}$, Melissa $\mathrm{McRae}^{2}$ and Lorraine Gordon ${ }^{3}$ \\ ${ }^{1}$ Talking Therapies Southwark, London, UK, ${ }^{2}$ Coventry \& Warwickshire IAPT, Coventry, UK and ${ }^{3}$ South London \& \\ Maudsley NHS Trust, London, UK \\ *Corresponding author. Email: leilani82000@yahoo.co.uk
}

(Received 1 December 2020; revised 16 August 2021; accepted 18 August 2021)

\begin{abstract}
This paper focuses on the Black minority ethnic population (Black British, Black African, Black Caribbean) and uses the term BME in reference to this group. Only 6.2\% of BME people access psychological intervention for common mental disorders. In provision of cognitive behavioural therapy (CBT) the diversity in global majority populations $^{1}$ requires culturally specific informed and responsive approaches. The Improving Access to Psychological Therapies (IAPT) programme needs to be accountable, culturally congruent and strategic, to ensure accessibility and improve outcomes for BME people. According to the Mental Health Foundation (2019), a higher percentage of Black, Asian and other minority ethnic populations (BAME) are diagnosed with common, severe and complex mental health disorders. Despite the weight of literature on this, little has changed. The NHS Implementation Plan outlines trajectories for increased access and reduced attrition within mental health services, addressing inequalities for BAME populations.

Evidence-based guidance and audits for provision of culturally sensitive and adapted therapies are presented in the pioneering (IAPT) BAME Positive Practice Guide (PPG). However, there are no funding arrangements or formal integrated frameworks to support implementation. The COVID-19 global pandemic and the high-profile death of George Floyd tragically exposed and highlighted the consequences of systemic racism. Understanding of the importance of service and clinical anti-racist practice is imperative for CBT therapists. Implementation of the BAME PPG audit tool ensures review of race equity in access, engagement, adaptation and workforce within IAPT and other mental health services. This could transform lives.
\end{abstract}

\section{Key learning aims}

(1) To understand the barriers (individual, societal and systemic) to accessing psychological therapies such as CBT and the impact on CBT treatment outcomes specifically for black minority ethnic (BME) populations.

(2) To recognise barriers to implementation of formal frameworks for equitable access to psychological therapies such as CBT for BME communities.

(3) To assist services and therapists to implement evidence-based learning, on cultural adaptations, to address barriers in access, retention and completion of CBT.

(4) To provide examples of services that have taken successful actions to address the issues identified in the earlier points.

\footnotetext{
${ }^{1}$ We recognise that the term BAME or BME may be unhelpful for individual communities (Milner and Jumbe, 2020). However, alternative terms used to group global majority, racially minoritised populations may not provide solutions. The BAME PPG 2019 is informed by targeted research in different minoritised populations to inform culturally responsive processes. The acronym in this context promotes focused work on specific communities. We pose suggestions for addressing these themes and developing this work in our summary conclusion.
} 
Keywords: Black minority ethnic (BME); CBT; cultural adaptations; primary care; secondary care; transcultural

\section{Introduction}

The COVID-19 pandemic and the Black Lives Matter demonstrations have shone a light on the various forms of racism experienced by black people in the UK and many other countries. Now more than ever, it is impossible for cognitive behavioural therapy (CBT) therapists, supervisors, services and commissioners to ignore the role that race and ethnicity plays in mental health disparities. Each of these overlapping groups need to reflect on their knowledge, skills and actions and consider their role in promoting equal access and outcomes for their patients.

This paper seeks to illustrate developments in improving under-representation of Black, Asian and other minority ethnic (BAME) access and engagement within Improving Access to Psychological Therapies (IAPT) services. It considers literature highlighting overrepresentation in secondary care and forensic services. We refer to a growing body of evidence exploring historical, current and societal related barriers to accessing primary care mental health for black minority ethnic (BME) populations. We begin to build on their recommendations to start to address these inequalities with a range of actions such as a funded formalised framework.

This paper cannot provide all the answers. The first part of the paper aims to discuss the historical and current societal impacts of systemic racism and funnel this down to the actions of mental health services and individual CBT therapists. Part 2 provides some suggestions on concrete actions that can be taken and demonstrates implementation of the IAPT BAME Positive Practice Guide (PPG) using Southwark IAPT as a case example (Beck et al., 2019).

\section{Part 1: Understanding historical, current and societal related barriers to accessing primary care mental health for BME populations}

\section{Context}

Historical context

Western mental health systems have historically exhibited racial bias. In January 2021, the American Psychiatric Association (APA) issued a formal apology to Black, Indigenous and people of colour, for its support of structural racism in psychiatry (American Psychiatric Association, 2021). With APA's roots of racism dating back to the 1700s, mental health diagnosis and treatment aligned with the era's racist social-political policies (American Psychiatric Association, 2021). This is evidenced in selective diagnostic criteria for mental illnesses to justify oppressive practices (Fernando, 2017). During this period, APA upheld racist beliefs regarding blacks being primitive and hostile, which had devastating consequences for their mental health 'care'. Black patients were segregated from whites and enslaved blacks used as payment for psychological treatment of whites. Interpretive comparative biological differences between whites and blacks have been used to uphold beliefs about inferiority of blacks, where the false rhetoric of Eugenics implied that blacks had smaller brains and were psychologically adolescent (Medlock et al., 2016).

For example, the 'Runaway slave syndrome': drapetomania was a formal diagnosis provided by white psychiatrists to justify abuse inflicted on slaves who attempted to escape from abusive slave masters (Colman, 2015). Severe beatings and toe amputations were medically prescribed to treat the 'mania': impulse to run away (Lipsedge and Littlewood, 2005). This was pathologised through beliefs that blacks lacked cognitive ability to desire or seek freedom and benefited from enslavement (Ruane, 2019). Rush proposed that black skin on black people was due to a form of leprosy, negritude (Hogarth, 2019). Pro-slavery advocates were in agreement, although not all physicians were of this opinion (Dumas, 2016; Myers, 2014). This evidences how scientific 
racism attempts to pathologise hypothesised constructions of race, which infer inferiority of racialised people and white superiority (Hogarth, 2017).

Although there has been some progress from slavery to the modern day, to some extent health advantages have become accepted as intrinsic to ethnicity (Byrne et al., 2020; Darlington et al., 2015; Fanon,1952; Medlock et al., 2016). Blacks are at increased risk of common mental disorder (CMD), yet more likely to receive pharmacological treatment and detention than psychological therapy. This suggests some bias in expectations/beliefs that this can be addressed, stemming from perceptions of cultural or genetic weakness as opposed to disadvantages due to socioeconomic inequalities, and ethnic discrimination (Byrne et al., 2020; Mason, 2003).

Race as a social construct is designed to maintain oppression and dominance of people considered inferior, with white considered the gold standard (Witzig, 1996; Zevallos, 2017). The dominance and assumed superiority of the social construct of Whiteness is illustrated through history (Frankenberg, 1993). Whiteness refers to invisible privileges and power which, via various ideological and cultural practices, systematically maintain structural, racialised and intersectional hierarchies and the oppression of people of colour (Carr, 2017).

The Slavery Abolition Act was passed in British parliament in 1833, which allegedly freed slaves across most British owned colonies. The legacy of slavery was not eradicated with centuries of oppressive economic and social practices. This presents implications for intergenerational trauma within the BME population (Fernando, 2017). From 1833 up until 2015, slave traders were in receipt of compensation (up to 17 billion pounds) for loss of earnings; slaves were considered business assets (Olusoga, 2018). Compensation records evidence that ancestors of David Cameron and George Orwell were among the beneficiaries (Jones, 2013). There is evidence of the presence of African Romans in Britain, dating back to the third century (Olusoga, 2016). Moreover, the famous Windrush marked the arrival of tens of thousands of individuals from the Caribbean in the late 1940s. Our government's campaign for workers from Commonwealth countries saw increased immigration from 1948 to 1970. The British Nationality Act (1948) gave citizens of UK Colonies the right of settlement in the UK (Jones, 1948), with working age adults and many children arriving, joining parents or grandparents in the UK, without their own passports.

Today systems and structures for marginalised groups can be oppressive. Understanding systemic forms of racialisation supports continued growth in equity of access and experience (McKenzie-Mavinga, 2009). Improved alliance can be developed when CBT therapists understand and acknowledge the historical context of the treatment of black people in various contexts which include health and mental health.

\section{Current societal context}

The socio-political landscape can impact the mental health needs of a population, and this is evident in the current COVID-19 pandemic. The devastating impact of discrimination was a correlating factor for higher risk of COVID-19 in BME people (Elwell-Sutton et al., 2020). The service of those on the frontline of health services is impeded by inequalities, which were an issue prior to COVID-19 (Kings Fund, 2020; Royal College of Psychiatrists, 2020). The phrase institutional racism was initially coined by Carmichael et al. (1992), referenced also in the Stephen Lawrence MacPherson report (MacPherson, 1999). This can be described as routine processes and procedures that translate into actions that negatively shape experiences of racialised groups within institutions (Nazroo et al., 2020). Disproportionality in BAME COVID-19-related deaths have highlighted these disparities.

Furthermore, both Brexit and the Windrush scandal have emphasised the effects of the 'hostile environment policy'. In 2018, the Home Office was exposed as failing to keep records of the legal status of British Caribbeans, and this led to mass evictions and deportation (BBC News, 2020; Gayle et al., 2020). This was met with public protests and pushback which resulted in a 
commitment to support and compensate those who have been affected (Quille, 2018). The commitment has not been upheld.

Public health experts have considered several explanations for the unequal disease burden for the UK BAME population. Razai and colleagues provided explanatory factors as socio-economic, underlying co-morbidity, cultural and epigenetic vulnerability, and occupational inequities (Razai et al., 2021). Williams concluded that racism and poverty could cause biological weathering and increase risk of chronic disease; he noted the implications for BME communities in poorer paid frontline, essential worker roles, statistically more likely to live in crowded accommodation and in deprived areas (Williams, 2020a). The ecological analysis of Nazroo and Becares of COVID-19related mortality rates and ethnic composition of the population accounted for age, population density, area deprivation and pollution; their findings concluded that entrenched systemic and institutional racism were root causes in higher prevalence of BAME COVID-related deaths (Nazroo and Becares, 2020).

These data expose the effects of structural inequalities with the potential for increased prevalence of traumatised and disenfranchised BME communities. As CBT therapists we need to consider societal context in the provision of culturally congruent clinical practice.

\section{Current mental health service context}

The Adult Psychiatric Morbidity Survey (McManus et al., 2016) indicated that BME communities are less likely to voluntarily seek support for mental health problems. Individuals from a BME background are four times more likely to be detained under the Mental Health Act and diagnosed with severe and enduring mental illness, compared with the white population (Barnett et al., 2019). BME groups are broadly perceived as hard to reach and engage with, within the mental health system. A weakness with this argument is that institutional barriers affecting attrition and access for this group are not considered (Joint Commissioning Panel on Mental Health, 2014; Naz et al., 2019; Nazroo et al., 2020).

Memon and colleagues' qualitative study (Memon et al., 2016), identified barriers to BME access of mental health provision, which included lack of cultural humility, discrimination and mistrust.

Psycho-social factors affect mental health, whether individuals are asylum seekers who have no recourse to public funds, or second or third generation BME communities. In the literature BME refugees are pre-disposed to common mental disorders through exposure to trauma through predisplacement, displacement, and post-displacement processes (Schlaudt et al., 2020). The South East London Community Health Study (SELCoH) using diverse population samples evidence links between discrimination, ethnicity and migration status (Hatch et al., 2016). Hatch and colleagues noted this causality for mental illness within BME populations, with indications that the Caribbean population were at highest risk (Hatch et al., 2011; Singh, 2019). A significant percentage of BME individuals are within low-income families where lack of information, opportunity and support networks will influence life choices and equity of access (Equality and Human Rights Commission, 2018).

Service users who experience themselves as the 'stigmatised other' tend to conceal their illness and experience a deleterious effect on the process of their recovery (Wong et al., 2017). For some service users, related to the perception of social stigma is low self-esteem, poor employment prospects, lack of money and altered behaviour from others (Corrigan et al., 2015). Crosscultural studies have identified social stigma against mental illness in Eastern Asian societies; for example, Japan has a tendency to delay accessing services (Zhang et al., 2020). Service users' self-concept and sense of social identity may be influenced by broader social factors. This may impede rejection of unhelpful labels, denoting negative stereotype, whilst acknowledging their own mental distress (Stuart, 2016). 
In order to address low rates of engagement and improve outcomes, service providers need to develop a good understanding of why there is the discrepancy for this population (Whittington and Grey, 2013). It is not enough to identify the existence of inequality for BME populations. This has been illustrated through literature over many years, with common themes consistently conveyed, yet little visible change following on from government strategies as indicated by the data in the Race Disparity Audit (Audit, 2018) and Equality and Human Rights Commission (2018). There is a necessity to move forward and address the differing barriers (Memon et al., 2016).

\section{Over-representation in secondary care}

In the last two decades numerous papers have examined the race disparities between underrepresentation of BAME communities in primary care and the over-representation in secondary adult mental health and forensic services. The Lammy Review (Lammy, 2017) estimated the cost of $£ 309$ million for over-representation in the Criminal Justice Courts. The Joint Commissioning Panel on Mental Health (2014) approximated the cost of race inequalities within in-patient and community mental health services at over $£ 100$ million. This was attributed to high BME prevalence and re-admissions on both psychiatric intensive care units (PICU) and medium secure care units. Therefore, the comparative individual service-user costs for BME were 58\% higher than white service users.

The report provides commissioners with useful guidance in tackling this. However, formal frameworks to resolve longstanding inequalities have not been nationally disseminated within IAPT. Despite specific recommendations for funding via Payments by Results (PBR) to be based on improved access for BAME populations in 2018, this was not implemented widely (NHS England, 2018).

BME people born in the UK are diagnosed with psychosis at a rate nine times higher than white British people (Kirkbride et al., 2010). This occurrence is related to social (isolation, alienation) and environmental factors rather than having a biological basis (Tortelli et al., 2015). Perkins and Repper (2020) argued that black people were more likely to be detained involuntarily under the Mental Health Act (1983) than other ethnic groups. Understandably, coercion fuels a perception that one will be intentionally harmed by others and may lead service users to mistrust health care providers so that working collaboratively to engage them in psychological therapies becomes an almost impossible task (Mercer et al., 2019). Clearly there is a need to promote cultural awareness within organisations to prevent people from minority ethnic groups being caught in a cycle of relapse and readmission under the provisions of the Mental Health Act (1983).

According to Gordon (2007), black service user and carer participants described the careful consideration of cultural diversity as essential to the provision of an acceptable service. When they perceived poor communication, with a lack of information sharing between carers and the mental health team, they found those factors affected their engagement. According to black service user participants, when there was a high perceived 'clash of interests' between mental health professionals and carers in relation to differences in culturally diverse beliefs and values, this was a barrier to accessing psychological therapies. Mental health professionals and service users in the study spoke about the importance of examining the process of engagement with carers. A service was considered 'hostile' when cultural sensitivity was low, and when it did not engage carers in a culturally congruent manner. In contrast, where there was a demonstration of adequate efforts to value cultural diversity, minoritised ethnic groups reported they would be more likely to engage.

\section{Under-representation in primary care mental health}

The Adult Psychiatric Morbidity Survey (2014) survey found that 14.5\% of white British aged 16 and over were receiving treatment for mental health compared with only $6.5 \%$ of BME. Data 
presented within the briefing paper by Carl Baker on Mental Health Statistics for England (Baker, 2020) appears to support this view of lower treatment rate. The paper highlighted that $23 \% \mathrm{BME}$ reported a common mental disorder compared with $17 \%$ white British. Yet they are not represented in primary care and are over-represented in psychiatric care (Mercer et al., 2019). In IAPT BME have high attrition rates and lower percentage of referrals, with $86 \%$ of selfreported referrals made to IAPT from white British backgrounds. Although there is no evidence that increasing BME access in IAPT will address over-representation in secure settings, studies indicate that social disadvantage and linguistic distance can create predisposition to psychosis (Jongsma et al., 2020). This is an area for further research; poor mental health correlates with less access to opportunity in education, community and employment (Haque et al., 2020).

The English IAPT is a country-wide initiative delivering psychological therapies recommended by the National Institute for Health and Care Excellence (NICE) for mild, moderate and severe common mental disorders (CMDs) in primary care (Clark, 2011; Clark, 2018). Although CBT is the primary treatment offered, therapy is not limited to CBT. Therapy is accessible using a stepped care model, based on severity of symptoms. IAPT pioneers ongoing transparency in recording of mental health outcomes and demographics of service users, which includes data on ethnicity (Clark et al., 2018). However, equitable access by ethnic populations is not currently set as a key performance indicator by the NHS.

IAPT has been demonstratively responsive to remote working and should commit further to learning and implementation of adaptations for increased access. IAPT is strategically placed to contribute to the working solutions in improving access and engagement for the BME population, which may be further compromised due to experiences relating to COVID-19 and accumulative racial injustices (Royal College of Psychiatry, 2020; Murray, 2020).

\section{National ethnic differences in access and recovery rates}

NHS England (2020b) have national data on numbers accessing services but not rates relating to ethnicity and the population within areas. Data on access by ethnicity are examined by some individual services and we will report on that in the next section.

The IAPT recovery rate of $50 \%$ was met by the white population averaging at $52.4 \%$, compared with black British Caribbean and black British African 49.4 and 48.3\%, respectively. However, there are substantial discrepancies between the rates of white British and BME communities in accessing IAPT. Invariably distinctions differentiating ethnic groups are not always recorded or lack specificity (Loewenthal et al., 2012). This indicates that BME retention, and numbers accessing and recovered at completion of treatment may be proportionately lower.

\section{The individual context: CBT therapist and patient}

The British Association for Behavioural and Cognitive Psychotherapies (BABCP) does not explicitly refer to cultural competence within their Standards of Conduct Performance and Ethics (BABCP, 2018), although several health professional associations reference this (Haarhoff et al., 2016).

An excerpt from their current standards is limited to: 'You must not allow your views about a service user's sex, age, colour, race, disability, sexuality, social or economic status, lifestyle, culture, religion or beliefs to affect the way you treat them or the advice you give. You must treat service users with respect and dignity. If you are providing are, you must work in partnership with your service users and involve them in their care as appropriate.' (p. 6).

A recent BABCP Diversity and Inclusion audit made recommendations for inclusive policy, procedure, campaigns and research including cultural competence training as accreditation 
criteria for CBT therapists, which would benefit the BME community (Murray, 2020). It is of note that BABCP's revision of training standards are currently at consultation stages.

\section{Understanding microaggressions in CBT}

The therapeutic alliance has been heralded as a key component for successful psychotherapy where emphasis is placed on the merits of unconditional positive regard (Okamoto et al., 2019; Rogers, 1957). The therapeutic alliance can impact access and retention of service users in mental health provision (Hartley et al., 2020). Implicit or explicit bias and microaggressions may threaten this (Sue et al., 2007). Microaggressions are intentional or unintentional racial slights or derogatory comments, and as therapists we need to be aware of our own assumptions, prejudices and stereotypes. The absence of this risks repetition and reinforcement of daily discrimination experiences for BME service users in the therapy room (Lago, 2011).

A review by Sue $(2010 \mathrm{a}, \mathrm{b})$ provided a taxonomy of aversive racism. These were identified as microassault, microinsult and microinvalidation, as illustrated and explained in Fig. 1 (Sue et al., 2007; Sue, 2010a,b).

In summary, microassault and microinvalidations are deemed unconscious (and thus unintentional) and microinsult as conscious. Microinsults are characterised primarily by a verbal or non-verbal attack meant to hurt the intended victim through name-calling, avoidant behaviour, or purposeful discriminatory actions. Terms intended to belittle and lead to questioning of one's identity effects motivation, causes low self-esteem and internalised prejudice (Saleem et al., 2020).

It is important to consider power dynamics between BME therapists and white patients, in addition to white therapists with BME service users and BME staff with white staff (Constantine and Sue, 2007). White therapists as members of the larger society may not be immune from inheriting the racial biases of their forebears (Burkard and Knox, 2004). A systematic review has evidenced how racism, prejudice and stereotype can impact on BME service user psychological safety (FitzGerald and Hurst, 2017).

Several papers have defined and conceptualised the impact of microaggressions (MA) on BME and BAME service users (Saleem et al., 2020; Solorzano et al., 2000; Sue et al., 2007; Williams and Halstead, 2019; Williams, 2020; Williams et al., 2020). Kanter and colleagues' randomised controlled trial indicated that therapists had difficulties acknowledging microaggressions or may be defensive; however, defiance may imply bias and in practice may pose demonstrative detrimental effects on emotional rapport and empathy (Kanter et al., 2020). The trial evidenced how workshops on cultural competence mindfulness in inter-racial interaction improved white therapists' emotional rapport and responsiveness towards BAME patients (Kanter et al., 2020). Williams and colleagues' Racial Harmony study evidenced ways of reducing microaggressions and improving inter-racial connections (Williams et al., 2020). Both Beck (2016) and Carter (1995) have suggested that transcultural therapy is more successful when white therapists are comfortable with difference and discussions on discrimination. We reference specific clinical examples in the next section of this paper.

\section{The individual context: $C B T$ therapists and service users}

Beck (2019; p. 2) noted that many CBT therapists 'may steer away from discussions on race' and the impact of racism on the service users' mental health. A 2016 qualitative study found that BME service users felt that therapists may not understand their presenting problem within their psychosocial context (Memon et al., 2016). The last few decades have seen recognition, identification and understanding of microaggressions within therapeutic settings. Therapists from all backgrounds need to bring this to their consciousness within their work. Table 1 illustrates examples that help explore subtle nuanced behaviour that can cause harm in relationships between both BME and 


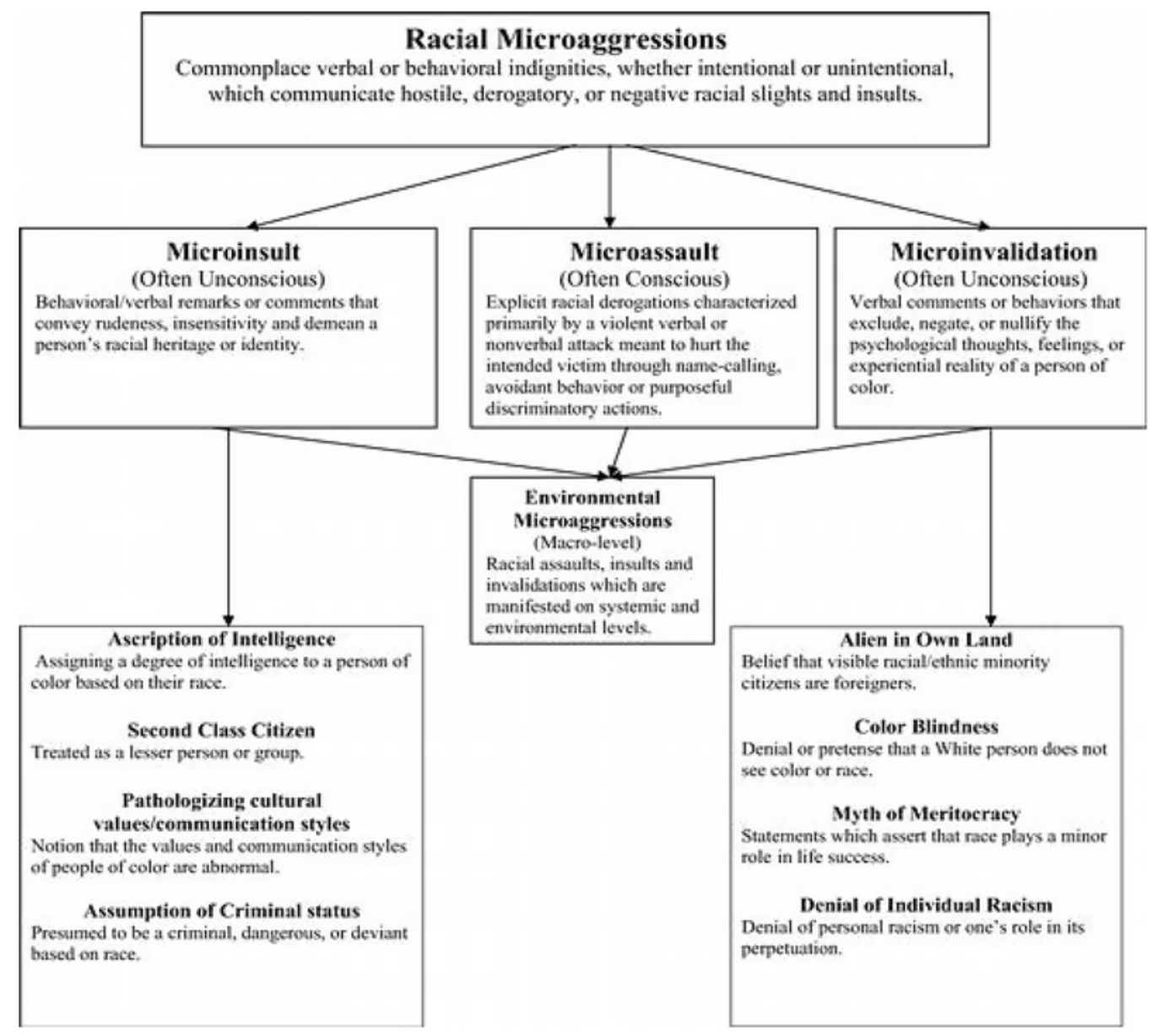

Figure 1. Racial microaggression categories and their relationships (Sue, 2010b; p. 29). Copyright @ 2010 by John Wiley \& Sons, Inc. All rights reserved. Reproduced with permission.

white therapists and white therapists and BME service users. Whist we cannot assume that there would not be potential for therapeutic ruptures between people from similar backgrounds, this depicts specific examples and implications of bias and prejudice.

Intended or not, in whatever form verbal indignities, unintentional physical responses of fear or disgust may occur, these frequent racialised slights serve only as a reinforcement that BME people do not belong, perpetuating negative stereotypes (Forrest-Bank, 2016). These examples are not there to shame or degrade, rather to educate and aid healthy discussion in safe spaces to explore issues within the therapeutic setting. There is much to learn about inclusive working and no one group, or person, has the monopoly on cultural competence (a concept difficult to measure; in relation to attainment, this is indeed a lifelong pursuit for us all). A recent literature review of related terms by Curtis et al. (2019) found definitions of cultural safety more helpful: 'a focus for the delivery of quality care through changes in thinking about power relationships and patients' rights'. This suggests that challenging our own culture and cultural systems engenders cultural protection (Curtis et al., 2019; p.12). We are in this together, no one person is immune to prejudice on a range of dimensions. These frameworks on issues of race may transfer to consideration of discrimination on other intersectional domains. As CBT therapists we all need to navigate towards more inclusive practice. 
Table 1. Examples of microaggressions in clinical practice

\begin{tabular}{ll}
\hline Types of microaggressions & Therapist and service users' examples \\
\hline Microassault & A white therapist responds to a service users' disclosure of distress linked to \\
exposure to racism and the therapist responds saying 'yes because you are a \\
BAME' without exploration of the impact, validation of emotions within therapy \\
formulation \\
1. A white therapist references interaction within a group therapeutic setting and \\
states that the older white middle-aged white su contributed well, despite being \\
positioned in between 'two big black men'. Inferring that the white lady's \\
positioning implied propensity for at risk or may have made her feel threatened. \\
Reinforcing the 'big black and dangerous' stereotyping \\
2. A senior black therapist has staff meeting with white colleagues, one of whom is \\
the said therapist's supervisee and the senior white therapist dismisses, belittles \\
and ignores contributions from the black therapist and focuses attention wholly \\
on the white colleague \\
1. In a group/individual therapeutic setting service user discloses racialised trauma \\
and reflects on impact. The white therapists do not formulate this in context of \\
difficulties - rushes ahead to the next step \\
2. A white therapist asks a black therapist to work with a black service user, whom \\
she perceives as difficult; 'interpersonally'. The request implies lack of reflexivity \\
or reflection on power imbalance and other factors which may impact their \\
therapeutic relationship. It suggests the white therapist may have negative \\
assumptions about working with BME communities. Implies that the problem lies \\
with the service user as opposed to considering their role in the therapeutic \\
ruptures
\end{tabular}

\section{Barriers to implementation of formal frameworks for equitable access to psychological therapies}

It has taken a global pandemic for calls for better funding and research for mental health (Holmes et al., 2020). Prevalence of common mental disorder within BME communities, linked to inequalities, is not a new phenomenon (Joseph Rowntree Foundation, 2016). The absence of key performance indicators (KPI) on diversity and inclusion, within IAPT services, suggests that addressing inequities in access are not IAPT core business. Funding to implement the pioneering BAME PPG guide (2019) has not materialised.

There is a need for local commissioning bodies to support a standardised formal framework, with related KPIs, otherwise services may struggle to implement the audit tool. At a recent Public Health England webinar, Williams gave examples of communities of opportunity (Williams, 2020). This included provision of care that addresses the societal context. As CBT therapists, supervisors and clinical leads, our work is greatly assisted by partnership working with both statutory and non-statutory organisations (Beck and Naz, 2019; Fountain et al., 2007).

\section{Formal frameworks for integrated BME access}

The model of Beck and Naz (2019) illustrates unmet need in the community and steps to address this. The bottom-up pyramid (see Fig. 2) displays a baseline of unmet need, with the peak representing recovery. It demonstrates barriers that BAME populations encounter at each level of the pyramid (Beck and Naz, 2019).

The diagram highlights the barriers to successful treatment from community to recovery stages. The narrowing of the pyramid is a visual representation of reduction in numbers before and after the assessment and treatment phase. The research of Beck and Naz (2019) indicated that poor conceptualisation impacted on drop-out rates, where there is an absence of formulation of racialised contexts. Several papers support the need for this, which we discuss below (Beck, 2019; Williams et al., 2018). 
Figure 2. The journey from having unmet need to successful treatment (Beck and Naz, 2019). Reproduced with permission.

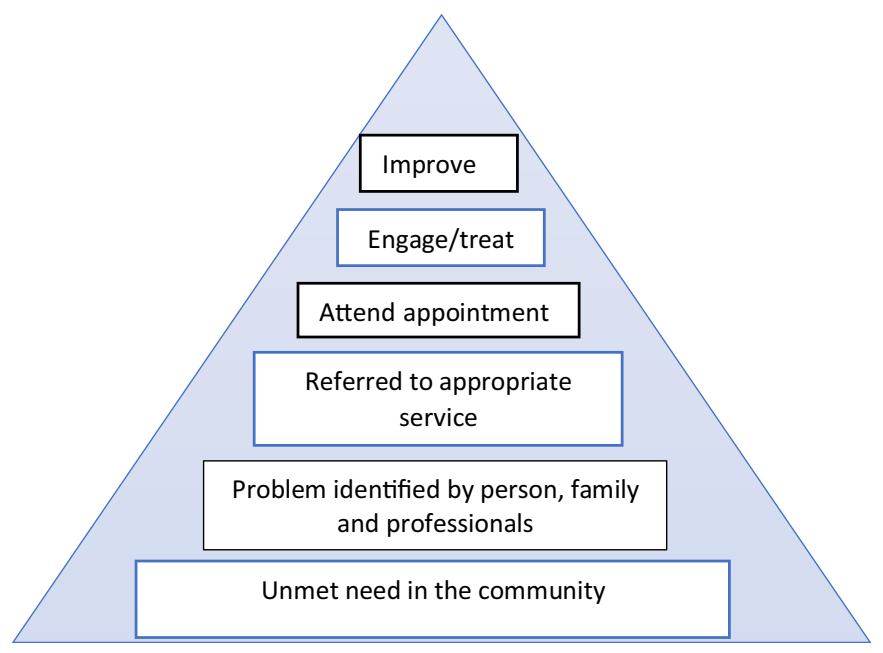

Their findings highlight how retention of service users can be improved from referral through to completion of treatment, by co-location of therapists (Fountain et al., 2007). To address unmet need access, attrition and recovery rates, we suggest co-location of CBT therapists within representative community groups. The presence of an IAPT therapist in these settings can evidence the value IAPT services place on the community. Statutory services within the community destigmatise mental health provision. With opportunities for reciprocal learning (Fountain et al., 2007) this may support IAPT services' ability to recognise, appropriately assess and treat CMDs across cultures. This infrastructure supports the development of representative research within these communities, which IAPT services are well positioned to support (Hakim et al., 2019).

Where therapists may lack the necessary skills to engage and successfully treat BME service users, mandatory training on cultural safety, cultural humility and white privilege may support this (Naz et al., 2019). This also poses implications for diversity training in CBT training programmes, of which we do not have the scope to review within this article. Although CBT models are idiosyncratic in nature, the CBT evidence base may not always be generalisable to BME or BAME populations. This is due to majority white homogeneity in research samples. Culturally congruent approaches need to be implemented and embedded within assessment and treatment formulation (Beck, 2019). IAPT may consider collaborative research and learning from experts in Afrocentric psychology approaches, to build a representative evidence base (Majors et al., 2020). A growing body of literature endorses service change and outreach work, evidencing improved access, experience and outcomes for BAME communities (Kada, 2019; Naz and Beck, 2019). The structure of CBT services has a role to play in assisting CBT therapists to address these needs.

\section{Part 2: Example of implementing the BABCP BAME Positive Practice Guide audit tool}

The 2019 BAME PPG audit tool aims to support services and clinicians to develop anti-racist practice. It covers four key areas: improving access, cultural adaptations, community engagement, and workforce and local population demographic.

There are numerous examples of good practice in inclusion work at Talking Therapies Southwark (TTS); a few will be elaborated upon in the next section. It is important to add that demanding IAPT targets and current commissioning equate to constraints in 
dissemination and development of some ideas. TTS staff members were inspired by the 2019 launch of the BAME PPG which sparked mobilisation of a BAME Positive Practice Initiative. TTS has set up a Positive Practice BAME working group with the following objectives:

(1) Share good practice and strategic ideas for implementation in increasing access for the representative Southwark populations.

(2) Share knowledge and methods on use of cultural adaptative/sensitive therapy.

(3) Provide reflective safe space to consider intersectional identities in the context of reflexivity and power imbalance in the therapy room.

The audit tool supports practical implementation of such initiatives. Services may consider identifying champions to lead in each of the four key areas. The time to develop this work requires recognition within core work targets. This section refers to findings of a review using this audit tool for TTS. Local Trust approvals were not required as data required was extracted from the national IAPT database.

\section{Southwark demographics}

Southwark is a richly diverse inner London Borough. Both deprivation and affluence are represented in neighbourhood wards. Just over half (54\%) of Southwark's population is of white ethnicity, a quarter (25\%) BME and a third of Asian (11\%) or other (10\%) ethnicities. This differs from the rest of London where a considerably smaller proportion (13\%) identify as black, and a considerably larger proportion identify as Asian (21\%). The ethnic diversity of the borough varies markedly across age groups and the population under 20 is much more diverse than other age groups, with a similar proportion of young people from white and black ethnic backgrounds (Council, 2019).

\section{Talking Therapies Southwark review}

The review (using the audit tool) identified robust screening policies and procedures where ethnicity is recorded of nearly $97 \%$ of open cases on the Southwark IAPT data set, allowing for a small percentage of service users who choose to not disclose their ethnicity. It was identified that providing a rationale for monitoring may support disclosure of ethnicity. Although data on ethnicity of referrals that do not reach screening stage are not captured, this implies the need to refine processes to obtain ethnicity recording on referral forms.

Reports demonstrate mapping of ethnicity of the population. Local authority Joint Strategic Needs Assessment (JSNA) data are consulted as they provide detailed analysis of local demographics, which was compared with TTS data.

The review confirmed that BME service users have a lower recovery rate than white British service users. The mean recovery rate for BME population was $48 \%$. The Bangladesh community has the only lower recovery rate compared with other ethnicities. Access rates are illustrated in Table 2.

With $25 \%$ of the Southwark population from BME backgrounds, this equates to 78,500 people of the total population of 314,200. 2955 referrals were made to Southwark IAPT for the 3rd quarter IAPT data set 2019/20, 630 of those were BME: 285 African, 180 Caribbean and 75 of mixed heritage, either White British and African or White British and Caribbean, with 90 any other Black background. This equates to $21 \%$ of total referrals (JSNA, 2018/19). What is significant is the difference in number of BME accessing services to number completing treatment and recovering; only 145 of 630 referrals completed treatment, less than $20 \%$. Recovery rates for Caribbean were $41 \%$, African $37 \%$ and $52 \%$ of any other black background. 
Table 2. Talking Therapies Southwark 3rd quarter dataset (2019/20): recovery by ethnicity

\begin{tabular}{lccc}
\hline Ethnicity & Recovery percentage & Reliable recovery & Reliable recovery percentage \\
\hline British & 56 & 180 & 51 \\
Irish & 50 & 10 & 50 \\
Any other White Background & 51 & 65 & 46 \\
White and Black Caribbean & - & - & - \\
White and Black African & - & - & 60 \\
White and Asian & 60 & 10 & 48 \\
Any other mixed background & 48 & 10 & 67 \\
Indian & 67 & - & - \\
Pakistani & - & -10 & 45 \\
Bangladeshi & - & 25 & 39 \\
Any other Asian background & 45 & 20 & 37 \\
Caribbean & 41 & 15 & 48 \\
African & 37 & 10 & 67 \\
Any other Black background & 52 & 5 & 19 \\
Chinese & 75 & 5 & 23 \\
Any other ethnic group & 19 & & \\
NULL & 23 & & 10 \\
\hline
\end{tabular}

This evidences that at least $80 \%$ of BME people drop out of therapy between referral, assessment and into treatment stages.

The most recent IAPT dataset confirmed that TTS do not currently have people accessing the service and completing treatment who fully reflect the population served. Action to remedy this is evidenced by the BAME Initiative working group, QI project targeted at BME communities, engagement with our South London and Maudsley (SLaM) Trust wide IAG (Independent Advisory Group) meetings, and development of an online Race Identity \& Me group. Table 3 displays the results of the BAME PPG audit tool for TTS.

Some materials in representative languages have been sourced from the Royal College of Psychiatry. Southwark work closely with the Multi-Ethnic Counselling service to provide service users the option of support in their first language, in addition to provision of interpreters where required within the service, although training has been delivered on depression and anxiety across cultures to CBT therapists within the SLaM trust within the last two years. This needs to be mandatory and delivered annually. TTS arranged further training which included cognitive behavioural therapists, counsellors, clinical psychologists, dynamic interpersonal therapists (DIT), eye movement desensitisation (EMDR) therapists, interpersonal therapists, and psychological wellbeing practitioners (PWPs).

The present context provides opportunities for virtual co-location, co-production and delivery. TTS therapists are usually co-located in GP services and Childrens' Centres. Mummies Republic $(\mathrm{MR})$ is an example of integrated community provision of psychological therapies. It is a partnership with the South London Mission church in Bermondsey, providing support for BAME mothers, many with no recourse to public funds and seeking asylum, hence being less likely to access traditional mental health provision, despite increased vulnerability to forms of abuse. Moving forward, services may need to consider development and delivery of digital therapies in partnership with community groups in the current absence of physical co-location, with potential virtual co-location and consultation with community groups, and co-production of materials with therapists and community representatives.

In TTS overall, there is good BAME representation in the workforce and the team broadly reflect the population served. BAME staff have equal access as white staff to continued professional development (CPD). The BAME network circulates information on the Workforce Race Equality Standards (WRES) courses for BAME staff (Chatwood, 2015). There is BAME representation in the workforce at senior level with three out of eight in the 
Table 3. BAME PPG standards 2019: improving access, adapting therapy, improving engagement, and workforce and staffing

Improving access BAME PPG standards

The service has mapped the ethnicity of the population served using appropriate convergent sources

The ethnicity of service users reflects the population served

Where the above is not the case, an action plan has been agreed to remedy this

BAME service users fare as well as White British service users in their clinical outcomes and level of satisfaction of using the service

Information leaflets are available in community languages

Information leaflets have been approved by service user representatives from the appropriate community

Staff have access to materials to support adapted therapy

\section{Adapting therapy access BAME PPG standards}

$100 \%$ of the clinical staff group have accessed CPD which included working with cultural diversity

$100 \%$ of the supervisors have accessed CPD which included working with cultural diversity (either therapeutically or in terms of providing supervision)

The service has looked at whether there is a need to develop provision in specific culturally adapted therapies

The service has shared values and practices to support the provision of culturally responsive therapies

Therapists have accessed specific training on working with asylum seekers and refugees where these populations are identified as having an unmet need

The service has a coherent policy for working with interpreters

There is training in basic principles of mental health and self-care available to interpreters Family members are not used as interpreters

Clinicians are allowed additional time for sessions where an interpreter is used

Clinical contact expectations are reduced where work involves interpreters

Interpreters are adequately prepared for the session before the appointment starts and have the opportunity for debriefing

Improving engagement BAME PPG standards

Workshops on mental health and accessing help are held with local BAME communities

Participation groups involve stakeholders who reflect the ethnic composition of the population served

The service has looked at whether there is a need to develop provision in specific culturally adapted therapies

BAME service users fare as well as White British service users in their clinical outcomes and level of satisfaction of using the service

Stakeholder groups include organisations that reflect the ethnic composition of communities served

\section{Workforce and staffing BAME PPG standards}

The clinical staff group broadly reflects that of the population served

Where this is not the case, an action plan has been agreed to remedy this N/A

The action plan has sufficient input from senior staff to be effective N/A

The senior staff group includes a range of ethnic diversity that reflects the community served

BAME staff development is guided by the WRES

leadership team being from BAME backgrounds, although there is more BAME representation at administrative and PWP levels than within Step 3 therapists. We need to consider broader implications for anti-racist practice in recruitment processes and clinical training. There is potential for conformity and confirmation bias (the tendency of people to favour information 
that confirms their existing beliefs or hypotheses) affecting employment diversity, through senior staff pre-conceived ideas about different social groups which may introduce discrimination (unconscious or otherwise) and impact the recruitment process (Agarwal, 2018).

If there are less BAME voices in senior positions, diversity of thought in decision making processes may be lacking and there is a distinct lack of power to implement inclusive practices. This is an example of systemic racism. SLaM NHS trust are committed to addressing this. The Psychology and Psychotherapy (P\&P) Race Equity working group aims to support projects that involve collaborative working with local community organisations and create an infrastructure for embedding anti-racist practice within the P\&P workforce. The group has asked to pool resources with the Patient Carer Race Equality Framework (PCREF) and the Trust BAME Network to ensure that its ambitions are continually informed by the needs and ideas of network members, patients, carers, and the community. Provision of resource and infrastructure from the Chief Executive Officer is imperative to ensure implementation. This would also evidence the commitment SLaM have made to reduce ethnic inequalities in mental health (NHS England, 2020c; Synergi Collaborative Centre, 2020).

Services could consider localised agreements on audit-review frequency, dependent on demonstrative progress towards the BAME PPG required standards. We suggest a traffic light system as a measure, where points allocated to each standard are collated and ranked from red (not met) to amber (working towards) and green (met), for clear identification of gaps to support agreed action plans.

\section{Conclusions}

The burden of inequalities is astronomical, and the potential societal, service and individual benefits surpass any investment (NHS England, 2020a). The devastating impact of inequalities caused by racism have been far reaching (Nazroo and Becares 2020; Nazroo et al., 2020), highlighting longstanding legacies of oppression within systems. We cannot right the wrongs of the past, but we can work to address the ongoing impact.

The demands of a target driven IAPT service mean it may be difficult to prioritise increasing access for BME communities without appropriate funding. Commissioning bodies have a responsibility to support services by funding frameworks which enable implementation of the BAME PPG 2019, principles of which are mirrored in the recent Advancing Mental Health Equalities strategy (NHS England, 2020c). This is the foundation for the provision of steps forward towards progressive change. This can only be obtained if the recommendations are enforced, learning recorded and next steps implemented. With considerable pressures on aspects of service delivery, a formal integrated framework would support this.

Representation of BAME staff and service users is imperative as we start to address the imbalance in mental health systems (BAME PPG, 2019; BPS, 2020). Targeted inclusive research for people from non-majority populations in the UK context is imperative in informing clinical practice. This also requires decolonisation of clinical curriculums to include teaching on both historical context and the social construct of race in black and white identities, where the re-accreditation process requires teaching programmes to evidence how they embed anti-racist practice throughout all training modules.

This is a call for action for the BABCP membership to step up in development of different strands of work for relevant representative communities that they serve, in support of cultivating community relationships and reciprocal learning. Where there is a shared commitment to be part of the solution, promoting individual and systems growth in development of cultural safety, humility, and intelligence is key. Our boldness in moving into uncomfortable territory will literally save lives. Understanding and accepting the need for 
anti-racist clinical practice may improve BME service users' experiences and outcomes in mental health.

Key practice points

(1) The evidence presented suggests that NHS England should fund, monitor, and hold commissioning bodies accountable for providing equitable access and outcomes for BME communities.

(2) Training on cultural safety and white fragility should be included within clinical courses and NHS mandatory training for all staff including CBT therapists.

(3) The use of the BAME PPG audit tool and service Positive Practice BAME working groups should be made compulsory within IAPT services (and equivalent within secondary care mental healthcare) to ensure regular review and assessment.

(4) Services should ensure diversity in all recruitment process (e.g. shortlisting panels, interview panel members) in order to support representative workforce recruitment.

Acknowledgements. None.

Financial support. No financial support was received.

Conflicts of interest. Leila Lawton and Melissa McRae are both members of the British Association for Behavioural and Cognitive Psychotherapies, Equality \& Culture Special Interest Group.

Ethics statement. Ethical approval was not needed for this paper.

Author contributions. Leila Lawton: Conceptualization (Lead), Resources (Lead), Validation (Lead), Visualization (Equal), Writing-original draft (Equal), Writing-review \& editing (Lead); Melissa McRae: Conceptualization (Supporting), Resources (Supporting), Validation (Equal), Visualization (Equal), Writing-original draft (Equal), Writing-review \& editing (Supporting); Lorraine Gordon: Conceptualization (Supporting), Resources (Supporting), Validation (Supporting), Visualization (Supporting), Writing-original draft (Supporting), Writing-review \& editing (Supporting).

\section{Further reading}

Beck, A. (2016). Transcultural Cognitive Behaviour Therapy for Anxiety and Depression: A Practical Guide. Routledge.

Beck, A., Naz, S., Brooks, M. and Jankowska, M. (2019). Black, Asian and Minority Ethnic Service User Positive Practice Guide.

Rathod, S., Kingdon, D., Pinninti, N., Turkington, D., \& Phiri, P. (2015). Cultural Adaptation of CBT for Serious Mental Illness: A Guide for Training and Practice. John Wiley \& Sons.

Williams, M. T., Rouleau, T. M., La Torre, J. T., \& Sharif, N. (2020). Cultural competency in the treatment of obsessivecompulsive disorder: practitioner guidelines. the Cognitive Behaviour Therapist, 13.

\section{References}

Agarwal, D.P. (2018). Here is how bias can affect recruitment in your organisation. Von Forbes (19 October 2018).

American Psychiatric Association (APA) (2021). Historical Addendum to APA's apology to black, indigenous and people of color for its support of structural racism in psychiatry. Published 18 January 2021, available at: https://www.psychiatry.org/ newsroom/historical-addendum-to-apa-apology (accessed 8 April 2021)

Audit, R. D. (2018). Summary Findings from the Ethnicity Facts and Figures Website. Cabinet Office.

Baker, C. (2020). Mental Health Statistics for England: Prevalence, Services and Funding.

Barnett, P., Mackay, E., Matthews, H., Gate, R., Greenwood, H., Ariyo, K., \& Smith, S. (2019). Ethnic variations in compulsory detention under the Mental Health Act: a systematic review and meta-analysis of international data. The Lancet Psychiatry, 6, 305-317.

BBC News (2020). Windrush scandal: Home Office showed 'ignorance' of race. Published: 19 March 2020, available at: https://www.bbc.co.uk/news/uk-politics-51961933 (accessed 8 April 2021).

Beck, A. (2016). Transcultural Cognitive Behaviour Therapy for Anxiety and Depression: A Practical Guide. Routledge. 
Beck, A. (2019). Understanding Black and Minority Ethnic service user's experience of racism as part of the assessment, formulation and treatment of mental health problems in cognitive behaviour therapy. the Cognitive Behaviour Therapist, 12.

Beck, A., \& Naz, S. (2019). The need for service change and community outreach work to support trans-cultural cognitive behaviour therapy with Black and Minority Ethnic communities. the Cognitive Behaviour Therapist, 12, E1.

Beck, A., Naz, S., Brooks, M. and Jankowska, M. (2019). Black, Asian and Minority Ethnic Service User Positive Practice Guide.

British Psychological Society (2020). 'Racial and social inequalities: Taking the conversations forward'. Retrieved from: https:// www.bps.org.uk/sites/www.bps.org.uk/files/Member\%20Networks/Divisions/DCP/Racial\%20and\%20Social\%20Inequalities\% 20in\%20the\%20times\%20of\%20Covid-19.pdf

Burkard, A. W., \& Knox, S. (2004). Effect of therapist color-blindness on empathy and attributions in cross-cultural counseling. Journal of Counseling Psychology, 51, 387

Byrne, B., Alexander, C., Khan, O., Nazroo, J., \& Shankley, W. (2020). Ethnicity, Race and Inequality in the UK: State of the Nation (p. 316). Policy Press.

Carmichael, S., Ture, K., \& Hamilton, C. V. (1992). Black Power: The Politics of Liberation in America. Vintage.

Carr, P. R. (2017). Whiteness and white privilege: problematizing race and racism in a 'color-blind' world and in education. In Rassismuskritik und Widerstandsformen (pp. 871-889). Springer VS, Wiesbaden.

Carter, R. T. (1995). The Influence of Race and Racial Identity in Psychotherapy: Toward a Racially Inclusive Model (vol. 183). John Wiley \& Sons.

Chatwood, E. (2015). Workforce Race Equality Standard Reports.

Clark, D. M. (2011). Implementing NICE guidelines for the psychological treatment of depression and anxiety disorders: the IAPT experience. International Review of Psychiatry, 23, 318-327.

Clark, D. M. (2018). Realizing the mass public benefit of evidence-based psychological therapies: the IAPT program. Annual Review of Clinical Psychology, 14, 159-183.

Clark, D. M., Canvin, L., Green, J., Layard, R., Pilling, S., \& Janecka, M. (2018). Transparency about the outcomes of mental health services (IAPT approach): an analysis of public data. The Lancet, 391, 679-686.

Colman, A. M. (2015). A Dictionary of Psychology. Oxford Quick Reference.

Constantine, M. G., \& Sue, D. W. (2007). Perceptions of racial microaggressions among black supervisees in cross-racial dyads. Journal of Counseling Psychology, 54, 142.

Corrigan, P. W., Bink, A. B., Fokuo, J. K., \& Schmidt, A. (2015). The public stigma of mental illness means a difference between you and me. Psychiatry Research, 226, 186-191.

Council, S. (2019). Southwark Health and Wellbeing Board: Joint Strategic Needs Assessment. Population Groups and Communities.

Curtis, E., Jones, R., Tipene-Leach, D., Walker, C., Loring, B., Paine, S. J., \& Reid, P. (2019). Why cultural safety rather than cultural competency is required to achieve health equity: a literature review and recommended definition. International Journal for Equity in Health, 18, 1-17.

Darlington, F., Norman, P., Ballas, D., \& Exeter, D. J. (2015). Exploring ethnic inequalities in health: evidence from the Health Survey for England, 1998-2011. Diversity and Equality in Health and Care, 12, 54-65.

Dumas, P. E. (2016). Proslavery Britain: Fighting for Slavery in an Era of Abolition. Springer.

Elwell-Sutton, T., Deeny, S., \& Stafford, M. (2020). Emerging findings on the impact of COVID-19 on black and minority ethnic people.

Equality and Human Rights Commission (2018). Is Britain Fairer? The state of equality and human rights 2018.

Fanon, F. (1952). Black Skin, White Masks Get Political. 2008 edition. Pluto Press.

Fernando, S. (2017). Institutional Racism in Psychiatry and Clinical Psychology. Palgrave Macmillan.

FitzGerald, C., \& Hurst, S. (2017). Implicit bias in healthcare professionals: a systematic review. BMC Medical Ethics, 18, 1-18.

Forrest-Bank, S. (2016). Understanding and confronting racial microaggression: An imperative for social work. Critical Social Work, 17(1).

Fountain, J., Patel, K., \& Buffin, J. (2007). Community engagement: the Centre for Ethnicity and Health model. Community Engagement: The Centre for Ethnicity and Health Model.

Frankenberg, R. (1993). White Women, Race Matters: The Social Construction of Whiteness. University of Minnesota Press.

Gayle, D., Taylor, D., \& Gentleman, A. (2020). Jamaica deportations 'must be halted until Windrush report published'. The Guardian, 7 February 2020.

Gordon, L. (2007). Applying Psychosocial Models of Psychosis and Working with Cultural Diversity. Unpublished thesis, City University Dissertation Library.

Haarhoff, B., Thwaites, R., \& Haarhoff, B. A. (2016). Reflecting on our socio-cultural background: becoming more culturally sensitive and effective CBT therapists. Reflection in CBT, 77-93.

Hakim, N., Thompson, A. R., \& Coleman-Oluwabusola, G. (2019). An evaluation of the transition from BAME community mental health worker to IAPT low intensity psychological wellbeing practitioner. The Cognitive Behaviour Therapist, 12. 
Haque, Z., Becares, L., \& Treloar, N. (2020). Over-exposed and under protected. The Devastating Impact of COVID-19 on Black and Minority Ethnic Communities in Great Britain.

Hartley, S., Raphael, J., Lovell, K., \& Berry, K. (2020). Effective nurse-patient relationships in mental health care: a systematic review of interventions to improve the therapeutic alliance. International Journal of Nursing Studies, 102, 103490.

Hatch, S. L., Frissa, S., Verdecchia, M., Stewart, R., Fear, N. T., Reichenberg, A., \& Hotopf, M. (2011). Identifying sociodemographic and socioeconomic determinants of health inequalities in a diverse London community: the South East London Community Health (SELCoH) study. BMC Public Health, 11, 861.

Hatch, S. L., Gazard, B., Williams, D. R., Frissa, S., Goodwin, L., SELCoH Study Team \& Hotopf, M. (2016). Discrimination and common mental disorder among migrant and ethnic groups: findings from a South East London Community sample. Social Psychiatry and Psychiatric Epidemiology, 51, 689-701

Hogarth, R. A. (2017). Medicalizing Blackness: Making Racial Difference in the Atlantic World, 1780-1840. UNC Press Books.

Hogarth, R. A. (2019). The myth of innate racial differences between white and black people's bodies: lessons from the 1793 yellow fever epidemic in Philadelphia, Pennsylvania. American Journal of Public Health, 109, 1339-1341.

Holmes, E. A., O’Connor, R. C., Perry, V. H., Tracey, I., Wessely, S., Arseneault, L., Ballard, C., Christensen, H., Silver, R. C., Everall, I., Ford, T., \& Bullmore, E. (2020). Multidisciplinary research priorities for the COVID-19 pandemic: a call for action for mental health science. The Lancet Psychiatry, 7, 547-560.

Joint Commissioning Panel on Mental Health (2014). Guidance for Commissioners of Mental Health Services for Black and Minority Ethnic Service Users. London, UK: Joint Commissioning Project on Mental Health. Available at: http://www. jcpmh.info/good-services/black-minority-ethnic-communities/ Google Scholar

Jones, J. M. (1948). British Nationality Act, 1948. British Yearbook of International Law, 25, 158.

Jones, S. (2013). 'Follow the money: investigators trace forgotten story of Britain's slave trade.' The Guardian Online. Retrieved from: https:/www.theguardian.com/world/2013/aug/27/britain-slave-trade

Jongsma, H. E., Gayer-Anderson, C., Tarricone, I., Velthorst, E., van der Ven, E., Quattrone, D., \& Lasalvia, A. (2020). Social disadvantage, linguistic distance, ethnic minority status and first-episode psychosis: results from the EU-GEI casecontrol study. Psychological Medicine, 1-13.

Joseph Rowntree Foundation (2016). 'Poverty \& Mental Health' Retrieved from: https://www.mentalhealth.org.uk/sites/ default/files/Poverty\%20and\%20Mental\%20Health.pdf

Kada, R. (2019). Cultural adaptations of CBT for the British Jewish Orthodox community. the Cognitive Behaviour Therapist, 12.

Kanter, J. W., Rosen, D. C., Manbeck, K. E., Branstetter, H. M., Kuczynski, A. M., Corey, M. D., Maitland, D. W., \& Williams, M. T. (2020) Addressing microaggressions in racially charged patient-provider interactions: a pilot randomized trial. BMC Medical Education, 20, 1-14.

Kings Fund (2020). Covid-19 has exposed 'deep inequalities and stark differences in life expectancy': The King's Fund responds to ONS statistics on Covid-19 deaths and socioeconomic deprivation (Press release). Retrieved from https:// www.kingsfund.org.uk/press/press-releases/covid-19-stark-differences-life-expectancy

Kirkbride, J., Coid, J. W., Morgan, C., Fearon, P., Dazzan, P., Yang, M., .. \& Jones, P. B. (2010). Translating the epidemiology of psychosis into public mental health: evidence, challenges and future prospects. Journal of Public Mental Health, 9, 4.

Lago, C. (ed) (2011). The Handbook of Transcultural Counselling and Psychotherapy. McGraw-Hill Education, UK.

Lammy, D. (2017). The Lammy review: an independent review into the treatment of and outcomes for, Black, Asian and Minority Ethnic individuals in the Criminal Justice System.

Lipsedge, M., \& Littlewood, R. (2005). Aliens and Alienists: Ethnic Minorities and Psychiatry. Routledge.

Loewenthal, D., Mohamed, A., Mukhopadhyay, S., Ganesh, K., \& Thomas, R. (2012). Reducing the barriers to accessing psychological therapies for Bengali, Urdu, Tamil and Somali communities in the UK: some implications for training, policy and practice. British Journal of Guidance \& Counselling, 40, 43-66.

MacPherson, W. (1999). The Stephen Lawrence Inquiry. Report of an Inquiry. United Kingdom: The Stationary Office.

Majors, R., Carberry, K., \& Ransaw, T. (2020). The International Handbook of Black Community Mental Health. London, UK: Emerald UK.

Mason, D. (2003). Patterns of and explanations for inequalities in health. Explaining Ethnic Differences: Changing Patterns of Disadvantage in Britain, pp. 121-138. Policy Press.

McKenzie-Mavinga, I. (2009). Black Issues in the Therapeutic Process. Macmillan International Higher Education.

McManus, S., Bebbington, P. E., Jenkins, R., \& Brugha, T. (2016). Mental Health and Wellbeing in England: The Adult Psychiatric Morbidity Survey 2014. NHS Digital.

Medlock, M., Weissman, A., Wong, S.S., \& Carlo, A. D. (2016). Addressing the legacy of racism in psychiatric training. American Journal of Psychiatry Residents Journal, 11, 13-13.

Memon, A., Taylor, K., Mohebati, L. M., Sundin, J., Cooper, M., Scanlon, T., \& de Visser, R. (2016). Perceived barriers to accessing mental health services among black and minority ethnic (BME) communities: a qualitative study in Southeast England. BMJ Open, 6, e012337. 
Mental Health Foundation (2019). Black, Asian and Minority Ethnic (BAME) Communities. Retrieved from: https://www. mentalhealth.org.uk/a-to-z/b/black-asian-and-minority-ethnic-bame-communities

Mercer, L., Evans, L. J., Turton, R., \& Beck, A. (2019). Psychological therapy in secondary mental health care: access and outcomes by ethnic group. Journal of Racial and Ethnic Health Disparities, 6, 419-426.

Milner, A., \& Jumbe, S. (2020). Using the right words to address racial disparities in COVID-19. The Lancet Public Health, 5, e419-e420.

Murray, K. (2020). Implications and Impact: A Case for Culturally Appropriate Mental Health Services in response to COVID-19. Retrieved from: http://www.bamestream.org.uk/wp-content/pdf/National-Mapping-of-BAME-MentalHealth-Services.pdf

Myers II, B. E. (2014). 'Drapetomania' Rebellion, Defiance and Free Black Insanity in the Antebellum United States. University of California, LA, USA.

Naz, S., Gregory, R., \& Bahu, M. (2019). Addressing issues of race, ethnicity and culture in CBT to support therapists and service managers to deliver culturally competent therapy and reduce inequalities in mental health provision for BAME service users. the Cognitive Behaviour Therapist, 12.

Nazroo, J., \& Becares, L. (2020). Evidence for ethnic inequalities in mortality related to COVID-19 infections: findings from an ecological analysis of England and Wales. medRxiv.

Nazroo, J. Y., Bhui, K. S., \& Rhodes, J. (2020). Where next for understanding race/ethnic inequalities in severe mental illness? Structural, interpersonal and institutional racism. Sociology of Health \& Illness, 42, 262-276.

NHS England (2018). IAPT Payment Case Study. Retrieved from: https://www.england.nhs.uk/wp-content/uploads/2018/04/ iapt-payment-casestudy.pdf

NHS England (2020a). Advancing Mental Health Equality Strategy. Retrieved from: https://www.england.nhs.uk/wp-content/ uploads/2020/10/00159-advancing-mental-health-equalities-strategy.pdf

NHS England (2020b). Improving Access to Psychological Therapies. Retrieved from: https://digital.nhs.uk/data-andinformation/data-collections-and-data-sets/data-sets/improving-access-to-psychological-therapies-data-set

NHS England (2020c). Advancing Mental Health Equalities. Retrieved from: https://www.england.nhs.uk/wp-content/ uploads/2020/10/00159-advancing-mental-health-equalities-strategy.pdf

Okamoto, A., Dattilio, F. M., Dobson, K. S., \& Kazantzis, N. (2019). The therapeutic relationship in cognitive-behavioral therapy: Essential features and common challenges. Practice Innovations, 4(2), 112.

Olusoga, D. (2016). Black and British: A Forgotten History. Pan Macmillan.

Olusoga, D. (2018). The Treasury's tweet shows slavery is still misunderstood. The Guardian, 12 February 2018. Available at: https://www.theguardian.com/commentisfree/2018/feb/12/treasury-tweet-slavery-compensate-slave-owners (accessed 8 April 2021).

Perkins, R., \& Repper, J. (2020). Compulsion and Race: Over-Representation and Time to Act Decisively. Mental Health and Social Inclusion.

Quille, N. (2018). The Windrush generation in Britain's 'hostile environment': racializing the crimmigration narrative. Criminal Justice, Borders and Citizenship Research Paper, 3274533.

Razai, M. S., Kankam, H. K., Majeed, A., Esmail, A., \& Williams, D. R. (2021). Mitigating ethnic disparities in Covid-19 and beyond. BMJ, 37.

Rogers, C. R. (1957). The necessary and sufficient conditions of therapeutic personality change. Journal of Consulting Psychology, 21, 95.

Royal College of Psychiatrists (2020). Impact of COVID-19 on Black, Asian and Minority Ethnic (BAME) staff in mental healthcare settings | assessment and management of risk. Available at: https:/www.rcpsych.ac.uk/docs/default-source/ about-us/covid-19/impact-of-covid19-on-bame-staff-in-mental-healthcare-settings-report-2020.pdf?sfvrsn=22a9083a (accessed 24 June 2020).

Ruane, M. E. (2019). A Brief History of the Enduring Phony Science that Perpetuates White Supremacy. Washington Post, 30.

Saleem, F. T., Anderson, R. E., \& Williams, M. (2020). Addressing the 'myth' of racial trauma: developmental and ecological considerations for youth of color. Clinical Child and Family Psychology Review, 23, 1-14.

Schlaudt, V. A., Bosson, R., Williams, M. T., German, B., Hooper, L. M., Frazier, V., . . \& Ramirez, J. (2020). Traumatic experiences and mental health risk for refugees. International Journal of Environmental Research and Public Health, 17, 1943.

Singh, S. P. (2019). How to serve our ethnic minority communities better. The Lancet Psychiatry, 6, $275-277$.

Solorzano, D., Ceja, M., \& Yosso, T. (2000). Critical race theory, racial microaggressions, and campus racial climate: the experiences of African American college students. Journal of Negro Education, 60-73.

Stuart, H. (2016). Reducing the stigma of mental illness. Global Mental Health, 3.

Sue, D. W. (2010b). Microaggressions in Everyday Life: Race, Gender, and Sexual Orientation. John Wiley \& Sons.

Sue, D. W. (ed) (2010a). Microaggressions and Marginality: Manifestation, Dynamics, and Impact. John Wiley \& Sons.

Sue, D. W., Capodilupo, C. M., Torino, G. C., Bucceri, J. M., Holder, A., Nadal, K. L., \& Esquilin, M. (2007). Racial microaggressions in everyday life: implications for clinical practice. American Psychologist, 62, 271. 
Synergi Collaborative Centre (2020). Pledge to reduce ethnic inequalities in mental health. Retrieved from: https:// synergicollaborativecentre.co.uk/ethnic-inequalities-pledge/

Tortelli, A., Errazuriz, A., Croudace, T., Morgan, C., Murray, R. M., Jones, P. B., Szoke, A., \& Kirkbride, J. B. (2015). Schizophrenia and other psychotic disorders in Caribbean-born migrants and their descendants in England: systematic review and meta-analysis of incidence rates, 1950-2013. Social Psychiatry and Psychiatric Epidemiology, 50, 1039-1055

Whittington, A., \& Grey, N. (eds) (2014). How to Become a More Effective CBT Therapist: Mastering Metacompetence in Clinical Practice, chapter 4 Diversity in CBT, Sharif El Leithy. John Wiley \& Sons.

Williams, D. (2020a). The Brain Architects Podcast: COVID-19 Special Edition: Creating Communities of Opportunity. Available at: https://developingchild.harvard.edu/resources/the-brain-architects-podcast-covid-19-special-edition-creat ing-communities-of-opportunity/ (accessed 8 April 8 2021).

Williams, M. T. (2020b). Microaggressions: clarification, evidence, and impact. Perspectives on Psychological Science, 15, 3-26.

Williams, M. T. (2020c). Psychology cannot afford to ignore the many harms caused by microaggressions. Perspectives on Psychological Science, 15, 38-43.

Williams, M. T., Kanter, J. W., Peña, A., Ching, T. H., \& Oshin, L. (2020). Reducing microaggressions and promoting interracial connection: the racial harmony workshop. Journal of Contextual Behavioral Science.

Williams, M. T., Metzger, I. W., Leins, C., \& DeLapp, C. (2018). Assessing racial trauma within a DSM-5 framework: the UConn Racial/Ethnic Stress \& Trauma Survey. Practice Innovations, 3, 242.

Williams, M.T., \& Halstead, M. (2019) Racial microaggressions as barriers to treatment in clinical care. Directions in Psychiatry.

Witzig, R. (1996). The medicalization of race: scientific legitimization of a flawed social construct. Annals of Internal Medicine, 125, 675-679.

Wong, E. C., Collins, R. L., Cerully, J., Seelam, R., \& Roth, B. (2017). Racial and ethnic differences in mental illness stigma and discrimination among Californians experiencing mental health challenges. Rand Health Quarterly, 6.

Zevallos, Z. (2017). Sociology of Race. The Other Sociologist, 9 June. Online resource: https://othersociologist.com/sociologyof-race/

Zhang, Z., Sun, K., Jatchavala, C., Koh, J., Chia, Y., Bose, J., .. \& \& Ho, R. (2020). Overview of stigma against psychiatric illnesses and advancements of anti-stigma activities in six Asian societies. International Journal of Environmental Research and Public Health, 17, 280.

Cite this article: Lawton L, McRae M, and Gordon L. Frontline yet at the back of the queue - improving access and adaptations to CBT for Black African and Caribbean communities. The Cognitive Behaviour Therapist. https://doi.org/ $10.1017 /$ S1754470X21000271 